\title{
SIMILAR SOUNDING WORDS WRITING STRATEGY BY LEARNERS OF MANDARIN AS A FOREIGN LANGUAGE
}

\author{
Lay-Hoon ANG ${ }^{1}$ \\ Hazlina ABDUL HALIM ${ }^{2 *}$ \\ 1,2 Department of Foreign Languages, Faculty of Modern Languages and \\ Communication, Universiti Putra Malaysia \\ 1hlang@upm.edu.my \\ ²hazlina_ah@upm.edu.my
}

Manuscript received 17 May 2018

Manuscript accepted 18 May 2019

*Corresponding author

https://doi.org/10.33736/ils.1601.2019

\section{ABSTRACT}

A general feature observed in foreign language classroom is the usage of communication strategies by the learners in their attempts to manipulate a limited linguistics system to communicate. This research aims to investigate the usage of similar sounding words as a written communication strategy in learning Mandarin. The respondents were 59 second- and third-year Malaysian students learning Mandarin as a foreign language at a public university. An open-ended questionnaire was set to gauge respondents' perception on the strategies used, and was divided into four parts, namely the demographic data and three parts of written tasks. The respondents were required to write a dialogue, answer questions on their hobbies, and construct sentences using the words given. A total of 77 instances of similar sounding words were found. The results showed that similar sounding words strategy was mostly applied to retroflex, alveolar, affricate, fricative, plosive, aspirated and unaspirated sounds. Another one third of the data consisted of syllables which were formed based on the learners' understanding of the pronunciation. It was found that the strategy provides constructive help in getting the message across despite the inaccurate pronunciation. The findings also mirror the constructive learning attitude and aggressive struggle put in by the learners, and therefore, a positive strategy that should be encouraged.

Keywords: language learning, Similar Sounding Words Strategy, Mandarin, Malaysian learners 


\section{Introduction}

Teaching Mandarin as a second or foreign language debuted as early as 1950 in China, with the enrolment of 33 international students from European countries. Consequently, language centres were set up in various cities in China within the following 16 years in the objective to accommodate thousands of learners who came from more than 60 countries in the world. The worldwide enthusiasm of learning Mandarin as a second language became much greater in recent years as a result of massive economic development and open policy by the Chinese government in late $20^{\text {th }}$ century.

In Malaysia, the teaching and learning of Mandarin as a foreign language at public universities started around 1970s. The classes at that point were conducted in a small scale by limited number of teachers. The number of higher institutions and private language centres which offer Mandarin classes, however, increases greatly in early $21^{\text {st }}$ century. In 2013, for example, Mandarin is offered as a proficiency course in all 20 public universities in Malaysia. At University Technology MARA (UiTM), Malaysia, as an example, approximately eight thousand students enrol in Mandarin course every semester at the main campus alone. Most Mandarin as a second language courses today inherit the general objectives to equip learners with basic communication skill of the language. In Malaysia, a common feature of all Mandarin as a foreign language courses is the ethnicity of the students. A majority of them are Malay while relatively few others are Indian, aborigine, and of mixed ethnicity.

Nevertheless, learning a new language at a matured age is never an easy task, particularly if the linguistic and cultural features of a new language differ greatly from one's daily language (Lado, 1957). Learners inevitably make mistakes due to insufficient knowledge and drills of the language at interlanguage stage. Regarding this, a general feature observed in foreign language classroom is the usage of communication strategies. As defined by Bialystok (1983), communication strategies are all attempts to manipulate a limited linguistics system in order to promote communication.

In this research, the researchers opted to investigate the use of one of the communication strategies by the learners, which is the "similar sounding word" strategy. According to Dörnyei and Scott (1997), this strategy refers to the use of an existing word which sounds similar to the intended one. Hence, the speaker compensates for a lexical item whose form he/she is unsure of with a word (either existing or non-existing) that sounds more or less like the target item. By using "similar sounding word" strategy, a learner attempts to achieve the communication goal with insufficient knowledge. Compared with avoidance strategy that gives up the effort of communicating or passing across a message by either stopping the sentence, abandoning the message or switching to other topics, "similar sounding words" is counted as a type of achievement strategy which should be encouraged, if communication problem is encountered. 


\section{Review of Literature}

There are many types of communication strategies identified by scholars throughout the years (Faérch \& Kasper, 1984; Yule \& Tarone, 1987), including interlingual strategies which outsource another language for remedy. These strategies include borrowing, lexical translation and foreignising. Intralingual strategies, on the other hand, attempt to resolve communication problems by using the same target language, by using approximation, word coinage, restructuring and appeals for assistance (Brown, 2000).

One major hurdle in acquiring a second language is the inadequacy of lexical items learnt. The learners may have also completely forgotten some words or are incapable of using some words confidently. Poulisse (1993) mentions that learners may resort to one of two main options in case of difficulties in lexical retrieval. They can either (1) abandon or change the original speech plan or (2) keep the macroplan unchanged and modify the preverbal message only. These two options are parallel to the dichotomy of reduction and achievement behaviours by Færch and Kasper (1983), and both processes can be further broken down into different types of solutions. Ringbom (2006) further added that learners tend to avoid certain words because they may not feel at ease with those words.

Nemati and Taghizadeh (2013) claim that the properties and procedures enveloping the mother tongue directly apprise the ways of which the second is learnt. In the framework of learning vocabulary in a different language, the difficulties are further compounded by language systems that are so patently different from a learner's native language. For example, the Chinese writing systems are tremendously different from alphabets to a large extent in terms of correspondence between their symbols and their sound systems (Everson, 1988). Not only the written scripts, even the pronunciation of Chinese languages (including Mandarin, Cantonese, and other dialects) is dissimilar to other languages. Trying to find equivalence in the sound system, especially Mandarin and other languages from different language groups, is proven next to impossible.

Due to its irregular sound-to-symbol correspondence, Chinese orthography is not always easy to decipher when the learners try to link the symbol to its sound. Learners with alphabetic language background, in which sounds, and symbols are tightly correlated, would have to come up with approaches to learning Chinese writing, both in word recognition and production. Recent Chinese as a Foreign Language (CFL) studies have focused on the relationship between Chinese character recognition and production (Ke, 1996, 1998; Kuo et al., 2015; Lam et al., 2018; Lin, 2000).

One hypothesis suggests an "orthographic depth" strategy (Liberman, Liberman, Mattingly, \& Shankweiler, 1980) of the Chinese writing system to predict the degree of learning difficulties to some extent. Some believe that the complexity of characters obstructs character recognition and production and finally the ultimate acquisition of characters (Hayes, 1987; Ke, 1996). Others recognise a strong correlation between being able to pronounce a word and being able to correctly identify its meaning (Everson, 1998; Yang, 2000). 
In term of strategies in learning Mandarin, Sung (2012) attempted to examine the most recurrently used Chinese-character learning strategies and factors underlying those strategies, and the association between learners' strategy use and their language performance. Sung (2012) found seven most frequently used strategies, four of which were stroke-orthographic knowledge-based, while the remaining three were phonological-semantics knowledge-based.

McGinnis (1999) conducted a study among learners in an intensive nineweek programme, with the purpose of discovering the strategies used in their learning of Chinese characters. The result indicated that students used various strategies when it comes to learning characters. These strategies included rote repetition, creating idiosyncratic stories about how the characters looked or how they were pronounced, and using the character's semantic or phonetic information in the character's components. Nevertheless, the students did not favour the latter strategy: they preferred making up stories or memoriaing the characters by rote means.

In the other study, Ke (1998) also tried to investigate learners' strategies of Mandarin students at the beginner's level and found that learners value the use of character components in learning the characters. Nonetheless, Ke (1998) discovered that learners placed more value on learning the characters holistically through repeated writing of characters, especially practising characters in terms of the twocharacter compounds rather than practising characters individually.

Based on the problems and some previous research mentioned above, the issues of learners' strategies have yet to be explored comprehensively. Hence, this study was carried out to investigate the communication strategy used by Malaysian learners in foreign language classroom. Specifically, the study focuses on the usage of similar sounding words as a written communication strategy in learning Mandarin. Hence, all the data are in the form of words.

\section{Methodology}

This research used simple quantitative and descriptive method of data analysis. The respondents were second- and third-year Malaysian students who learn Mandarin as a foreign language at a public university. A total of 59 respondents participated in this study. There were five males and 52 females, aged around 20-22 years old. In terms of ethnicity, all of them were Malay except an Indian, a Kadazan, an Iban and two Chinese-Malay respondents. A majority of them acquired Malay language as their first language. Only five of them spoke English as their mother tongue, one spoke Tamil, and another spoke Iban language. In terms of daily language, a majority of them spoke Malay language, only one spoke Tamil, while 16 of them use English frequently in daily communication. A total of 44 participants were learning Mandarin at level two while 15 others at level three during this study. As there are 42 hours for each level, it can be assumed that all of them had at least 42 hours formal learning of Mandarin, and a quarter of them had learned at least 84 hours of Mandarin. This brief piece of information reveals that the participants were used to Malay or other languages for more than 20 years and their Mandarin proficiency was only at the beginning stage of about $42-84$ hours. 
In order to find out the communication strategies that participants might have used to overcome the inadequacy of language proficiency, a questionnaire was set as the instrument of the study. The questionnaire comprised four parts, namely, the participant's language information, and three parts of written tasks. The respondents were required to write a dialogue about daily activities, answer three open-ended questions regarding their hobbies, and construct six sentences using the words given. To ensure that the strategies are detectable, the participants were not allowed to erase but to strike through any word if they wanted to make changes. The participants were free to write in any form, such as Chinese character, hanyu pinyin (the Romanised written Chinese phoneme), punctuation, or even a mixture of different forms of word, if they had to.

\section{Findings and Discussion}

In this study, 16 types of communication strategies had been identified. Among some intralingual achievement communication strategies found were retrieval (68 instances), the use of all-purpose words (59 instances), approximation (58 instances), over-explicitness (51 instances), restructuring ( 8 instances), word coinage ( 2 instances) and circumlocution ( 2 instances). The frequencies were rather small for the latter three strategies probably due to the extra writing and language skills required which are beyond their ability. On the other hand, there were also a few interlingual communication strategies noted in the data, such as literal translation (47 instances) and code switching (36 instances). Out of these communication strategies, the strategy of using similar sounding words was found to be the third most popular strategy, placed after font switching from Chinese script to Hanyu Pinyin (365 instances) and self-repair strategy (198 instances). These two most popular strategies were easily noted due to the traces left behind by participants such as change of written scripts, scratched marks or strike though lines. Similar sounding strategy belonged to intralingual strategy as only the same language is used, of which in this case, Mandarin. A total of 77 instances were found.

From the analysis, the similar sounding words were noticed to linger around 14 types of words or sound elements (Table 1). These similar sounding words can actually be categorised into five major groups, namely, spelling (38 instancs), affricate-fricative (19 instances), finals (9 instances), homonym (6 instances), and plosive (5 instances).

From the written tasks, it was found that only six participants wrote purely using Chinese characters, others seemed to depend heavily on hanyu pinyin. There were 12 instances totally in hanyu pinyin, while majority (41 instances) are in a mixture of Chinese characters and hanyu pinyin.

The usage of similar sounding words strategy by learners was found to take place in three forms, firstly the morphological construction, secondly the phonetic construction and thirdly homonym. The results showed that about half of the strategies (38 instances) were bound to the morphological construction. These data looked like misspelt syllables or wrongly formed syllables which sounded close to the actual pronunciation. Another 38 instances were related to phonetic construction. The strategy of similar sounding words was mostly applied to some 
particular sounds only, namely, retroflex, alveolar, affricate, fricative, plosive, aspirated or non-aspirated sounds. It was mainly because the accurate sound cannot be confirmed by the learners.

Table 1

Grouping of similar sounding words

\begin{tabular}{|c|c|c|c|}
\hline Category & Type of Similar Sounding Words & No. & Total \\
\hline \multirow[t]{3}{*}{ spelling } & 1. different spelling & 30 & \multirow{3}{*}{38} \\
\hline & 2. missing ending & 3 & \\
\hline & 3. extra ending & 5 & \\
\hline \multirow[t]{7}{*}{$\begin{array}{l}\text { affricate - } \\
\text { fricative }\end{array}$} & $\begin{array}{l}\text { 4. unaspirated retroflex affricate } z h \text { and unaspirated } \\
\text { alveolar affricate } z\end{array}$ & 4 & \multirow{7}{*}{19} \\
\hline & $\begin{array}{l}\text { 5. aspirated retroflex affricate } c h \text { and aspirated alveolar } \\
\text { affricate } c\end{array}$ & 6 & \\
\hline & 6. voiceless retroflex fricative $s h$ and alveolar fricative $s$ & 1 & \\
\hline & $\begin{array}{l}\text { 7. retroflex affricate/ fricative } z h-c h-s h \text { and alveolar } \\
\text { affricate/ fricative } z-c-s\end{array}$ & 5 & \\
\hline & $\begin{array}{l}\text { 8. alveolo-palatal affricate } j-q \text { and alveolo-palatal } \\
\text { fricative } x\end{array}$ & 1 & \\
\hline & 9. alveolo-palatal fricative $x$ and alveolar fricative $s$ & 1 & \\
\hline & 10. voiced retroflex fricative $r$ & 1 & \\
\hline \multirow[t]{2}{*}{ plosive } & $\begin{array}{l}\text { 11. unaspirated velar plosive } g \text { and aspirated velar } \\
\text { plosive } k\end{array}$ & 3 & \multirow[b]{2}{*}{5} \\
\hline & $\begin{array}{l}\text { 12. unaspirated alveolar plosive } d \text { and aspirated } \\
\text { alveolar plosive } t\end{array}$ & 2 & \\
\hline finals & 13. finals $i-e$ & 9 & 9 \\
\hline homonym & 14. substitution with Chinese homonym & 6 & 6 \\
\hline \multicolumn{2}{|l|}{ Total } & \multicolumn{2}{|c|}{77} \\
\hline
\end{tabular}

\section{Morphological Construction in Spelling}

From the results, it is found that similar but inaccurate spelling is most widely used among all types of similar sounding words strategy by the participants (38 instances). This particular type of similar sounding words applied to data which are written in hanyu pinyin only. The hanyu pinyin is spelt ambiguously based on the learners' understanding of the pronunciation. This similar but inaccurate spelling reflects the incomplete learning of the participants.

The similar spelling strategy takes place in a few ways of morphological construction. Basically, it involves consonant, vowel, or both consonant and vowel of a syllable. These similar sounds, especially when pronounced in a string of utterance as a sentence, may not be easily distinguished from the original sounds, unless the listener has a very sharp listening skill to catch the inaccurate pronunciation or the utterance is made too obvious that alerts the listener to the mistake.

The track of strategy, however, is very clear when the learners are asked to put the sound in writing. They have to spell out each alphabet and thus even minor 
difference such as "oa" or "ua" can be detected. Listed below are some examples of similar spelling strategy that involved consonant only. [Note: P: number of participant; T: Translation; ( ) correct spelling]

1) P8 : tia (xia) wu wo qu shi tang chi $\mathrm{T}$ : I will be going to the canteen for fan, ni ne? food in the afternoon. How about you?

2) P31: 我的手机 kuai (huai)le.

$\mathrm{T}$ : My mobile phone is out of function.

3) P1: Wo qu tu syu (shu)guan.

T: I go to the library.

From these examples, it can be seen that similar sounding words were used because the participants were not sure of the exact pronunciation in Mandarin. The structure kuai exists in hanyu pinyin and thus looks normal even though it does not carry the intended meaning. On the contrary, the combinations tia and syu do not exist at all in hanyu pinyin. These structures clearly uncover the participants' strategy in applying an ambiguous spelling to camouflage their uncertainty of the words.

More examples of similar spelling are found in certain vowels, especially ao, $o u, o a$ as in the following examples.

4) P36: 我xi huan 吃 man tao(tou). T: I like to eat Chinese plain bun.

5) P7: wo xi huan chi man toa (tou). T: I like to eat Chinese plain bun.

6) P51: women duo (dou) qu ma? T: Are we all going?

7) P57: wo you (yao) chi mifan. T: I want to eat rice.

8) P64: wo yau (yao) qu yin hang qu T: I want to go to the bank to withdraw qian. some money.

9) P7: wang lao shi jioa (jiao)wo yue T: Teacher taught me reading. du ke.

10) P1: 有空时, 我喜欢做 lui (lian) T: During free time, I like to do some $x i$. exercise.

The examples above highlight the fact that the morphological structure in similar sounding word strategy may vary from person to person. For ou sound, some participants may put a closer sound as ao, as in example (4) by P36, or oa, as in example (5) by P7, or uo in example (6). The ao sound is replaced by similar sound spelt as ou by P57, as in example (7), but as au by participant 64, as in example (8). Likewise, the same strategy applied for iao sound is spelt as ioa in example (9) by P7 and ian as ui in example (10) by P1. 
From the examples, we can conclude that similar sounding word strategy in Mandarin share a common feature: they are noted to carry at least one vowel that is the same as the original sound. For example (4)-(7), $O$ is found in both versions, either original or similar sound. The $o$ in example (4)-(7), $a$ in example (7)-(9), and $i$ in example (9)-(10) are found in both original or similar sound versions. The shared vowel enables the words to sound similar.

Two other features that make the words similar to the original are addition or omission of $n$ or $n g$ at the end of vowels. In example (11) and (12) below, the ending of pen and guan is short of a $g$. On the contrary, the pang in example (12) is given an extra $g$. Both additional and shortage of alphabet are indicators of the participants' effort to get to the sounds required with their limited competency.

11) P7: zhe shi wo pen (peng) you de T: This is my friend's handphone. shou ji.

12) P59: wo yao (you) yi bai zhang yin $\mathrm{T}$ : I have 100 musical $\underline{\mathrm{CD}}$. yue guan (guang) pang (pan).

\section{Affricate and Fricative Sounds}

In Mandarin, there are a few unique sounds that are too difficult to be differentiated by non-native speakers who come from different phonetic background. The affricate $z h, c h, z, c, j, q$ and fricative $s h, s$ and $x$ in Mandarin are normally considered top in the list of problematic sounds to Mandarin learners. These few sounds are unique and do not have equivalence in the language systems such as English or Malay language.

In this study, the communication strategy of similar sounding words is related to affricate and fricative sounds, listed the second most common strategy by Mandarin learners. A total of 19 instances were found. Based on the similarity of sounds, these data can be divided into the following four groups as shown below.

\section{i. retroflex affricate and alveolar affricate.}

These two affricate sounds in Mandarin are easily mixed up by the learners due to the similarity of articulation process. The sounds involved are retroflex and alveolar. The simple way to explain the difference between the two is that retroflex sounds are pronounced with the tongue curled upwards and touching the hard palate while forcing the air out. On the other hand, alveolar sounds differ by letting the tongue lie flat instead.

In fact, based on the aspiration feature, there are two pairs of affricates. First, unaspirated retroflex affricate $z h$ and unaspirated alveolar affricate $z$, and second, aspirated retroflex affricate $c h$ and aspirated alveolar affricate $c$. The difference in retroflex and alveolar affricates only lies in the existence of $h$ in written form. There is a $h$ for retroflex affricate $z h$ but no $h$ for alveolar affricate $z$. In this research, the respondents were found to use the sound in the same pair as a communication strategy to present words which they were not sure of. In examples (13) and (16), the participants P20 and P60 used retroflex affricate in the place of 
alveolar affricate by adding an extra $h$, while it is the contrary for participant P62 in example (14) and participant P9 in example (15) who dropped the $h$.

13) P20 : Ni de man tou zhen (zen) me $T$ : How is your Chinese plain bun? Is it yang? Hao chi? delicious?

14) P62: 这是我的家的zao (zhao)

$T:$ This is the picture of my family.

pian.

15) P9 : 你xi huan $\underline{\underline{i}}$ (chi) 什么?

$\mathrm{T}$ : What do you like to eat?

16) P60: wo wu dian qu chao (cao) $\mathrm{T}$ : I go to the field to exercise at 5 chang duan lian shen ti. o'clock.

\section{ii. retroflex fricative and alveolar fricative.}

Some foreign language learners were found to have the tendency of using a sound which shares a common feature or belongs to the same phonetic category whenever they were unsure of the pronunciation. This psychology is applied by learners in Mandarin pronunciation not only to retroflex affricates $z h, c h$ and alveolar affricates $z, c$, but also to retroflex fricative sh and alveolar fricative $s$. In example (17), participant P1 knew that she had to choose a fricative but her uncertainty of the word was revealed when she wrongly chose an alveolar fricative instead of retroflex fricative.

17) P1: Wo zhi si (shi) di yi ke (ge) chi man tao (tou) eh.

T: I only being the person to eat Chinese plain bun.

\section{iii.retroflex affricate/fricative and alveolar affricate/fricative.}

While learning the phonemes, the learners are introduced to affricate and fricative sounds in Mandarin consecutively in a row, that is $z h, c h, s h, r$ and $z, c, s$. To many foreign language learners, these sounds are very much alike. It is, therefore, not surprising to find such similar sound words used as a substitution for one another in the data. The results showed that unaspirated affricate $z h, z, j$ and aspirated affricate $c h, c, q$ are found rather mixed up. Fricative $s h, s, x$ are also found to be substituting one another. Even an aspirated retroflex affricate ch was found to be similar and was sometimes used instead of unaspirated alveolar affricate $z$ or unaspirated retroflex affricate $z h$, as in examples (18) and (19). A retroflex fricative $r$ was wrongly attached to final $e$ by participant P1 in example (20). The usage of similar sounding words always ends up with errors in the learners' scripts but it shows the strategic effort that the learners put in to get the correct words. The participants were found to swap retroflex sound and alveolar sound as these two are the most alike compared to others such as plosive or palatal. 
18) P2: 我要吃 bao chi (zi).

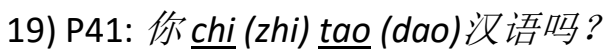

20) P1: Wo er (e) le.
$\mathrm{T}$ : I want to eat bun.

$\mathrm{T}$ : Do you know Chinese language?

T: I am hungry.

Though leaving behind a bad impression of the inaccurate pronunciation, the use of similar sounding words strategy is helpful most of the time because an alveolar affricate or fricative, which is easier to pronounce and common in the mother tongue, sounds similar to a retroflex affricate or fricative and always enable listeners to guess the meaning and get the message across. As long as the choice made in the communication strategy does not coincidently carry a diversified or far deviated meaning, similar sounding word strategy in the case of alveolar and retroflex is easy to apply and worth trying.

\section{iv. alveolo-palatal affricate / fricative and alveolar fricative.}

In Mandarin phonetic system, another group of problematic phonemes to beginners is alveolo-palatal which consists of unaspirated alveolo-palatal affricate $j$, aspirated alveolo-palatal affricate $q$ and alveolo-palatal fricative $x$. To some learners, these alveolo-palatal sounds are so similar that they are not only hard to be differentiated among themselves but also sound like alveolar group which consists of unaspirated alveolar affricate $z$, aspirated alveolar affricate $c$, and alveolar fricative $s$. The communication strategy of using similar sounding words is evident in the interchangeable use within this alveolo-palatal group, as $j$ and $q$ in example (21), and also with alveolar set of sounds, such as $s$ in example (22).
21) P25: 你是不是坐 $i i$ (qi) 车去?
$\mathrm{T}$ : Are you going by car?
22) P1: In (Yin) wei wo si(xi) huan
T: Because I like Chinese plain bun.

$$
\text { man tao (tou). }
$$

The rather frequent use of the similar sounding word in this particular group for affricate $z h, c h, z, c, j, q$ and fricative $s h, s$ and $x$ can be explained. These sounds share a common feature especially friction during articulation. However, they are made different by other features especially location of tongue which thus form alveolar, alveolo-palatal or retroflex sounds. These different combined sets of features are further multiplied by adding another feature which is either aspirated or unaspirated. The learners are smart enough to identify these affricates and fricative sounds as a group which have similar pronunciation. In the examples of similar sounding words strategy, it is noticeable that affricate $z h, c h, z, c, j, q$ and fricative $s h, s$ and $x$ are used randomly in replacing any sound that falls under this group. 


\section{Plosive Sound}

Besides affricate and fricative, similar sounding word communication strategy is also applied to another consonant part, namely, plosive sound. There are three types of plosive sounds. First, unaspirated bilabial plosive $b$ and aspirated bilabial plosive $p$; second, the unaspirated alveolar plosive $d$ and aspirated alveolar plosive $t$; and third, unaspirated velar plosive $g$ and aspirated velar plosive $k$. Bilabial plosive $b$ and $p$ are not found in the data collected in this study.

As compared to 19 instances for similar sounding words strategy related to affricate and fricative sounds, only five instances of similar sounding words strategy involved plosive sound. Other than example (19), another example of similar sounding word strategy related to plosive sound is given in example (23), of which the unaspirated velar plosive $g$ is replaced by aspirated velar plosive $k$.

\section{3) P1: ni chi ji ke (ge)? T: How many have you eaten?}

Due to the common articulatory feature of these plosive sounds, the plosive sounds, either alveolar $d$ and $t$, or velar $g$ and $k$, or even bilabial $b$ and $p$, are very similar. These pairs of plosive sounds are merely differentiated by the aspirated or unaspirated feature. In the eyes of learners, these aspirated or unaspirated sounds are somehow switchable and even replaceable. As the articulatory organs used are the same, the confusion and misunderstanding caused is less noticeable and not as serious as affricate and fricative sounds. However, as every initial and final differentiates and determines the meaning in tonal language, the plosive sounds, of course, should not be replaced by other plosive sounds.

In fact, the application of similar sounding words communication strategy is most likely influenced by the other languages acquired by the participants especially the mother tongue or English language. In Malay language, alveolar $t$, velar $k$, or bilabial $p$ are pronounced unaspirated. Therefore, the unaspirated plosive is used in the place of aspirated plosive sounds in Mandarin. The usage of similar sounding words as a communication strategy also indicates the participants' awareness on the similarity of the phonetic features of plosive sounds.

\section{Finals i-e}

Most of the types in communication strategy of similar sounding word found in this study are concerning initials (consonants), such as plosive, fricative and affricate. Out of 77 instancs, there are only nine cases are related to finals, especially $i$ and $e$ sounds. These two finals are considered confusing to learners. For example, quite a number of learners could not differentiate zhi and zhe, chi and che, ri and re. To handle this problem, some learners opted for the communication strategy of similar sounding words with the hope that they might have a higher chance to get the correct sound. The three instances of such usage are shown in examples (24) to (26).

24) P3: Wo che (chi) mian tiao he bao zi. T : I eat noodle and bun. 
25) P64: Wo men zuo chi (che) qu yin T: We take a car to the bank. hang.

26) P41: Wei shi (shen) me ni chi hen $\mathrm{T}$ : Thanks for having meal with me. tuo(duo) man tao (tou)?

Finals $i$ and $e$ are obviously misplaced in these three sentences. The participants spelt chi as che, che as chi, and shen as shi. Though all spellings are incorrect, the meaning can still be guessed based on the context and the similar sound of the syllable. The strategy is thus seen as a good attempt by the participants to get the correct spelling or convey the meaning.

\section{Chinese Homonym Characters}

As the research design focussed on the written aspect of communication strategy, this study investigated how the foreign language learners manipulated the Chinese characters to achieve their communicative purpose. In most cases (or 71 out of 77 cases), hanyu pinyin is used as an alternative to substitute Chinese characters that cannot be written by the participants. There are, however, 47 cases that involve the usage of Chinese characters, either totally or partially.

One of the unique features of Chinese characters is homonym. It refers to words that have similar pronunciation but carry different meanings. For example, 和, 合,何,河 are homonyms with the same pronunciation hé but the meaning are distinguished by the structure and component elements of the characters. There were as many as six participants who applied the communication strategy related to homonym. The usage of homonym is not frequent due to the requisite that the participants must have the knowledge of other Chinese characters which share the same phonetic features. Without any homonym in mind, it is impossible to apply this communication strategy. The usage of this unique written strategy can be explained based on examples (27) and (28).

27) P12: 你合 (和) 我 yi qi 去 chaoshi, T : Would you like to go with me to the 好吗? supermarket?

28) P20: 你习环 (喜欢) 吃什么?

$\mathrm{T}:$ What would you like to eat?

These two examples above, in fact, demonstrate two different methods applied in the same communication strategy of homonym. The former is based on a comprehensive similar sounding word strategy which involves the syllable and also the tone of the homonym. The latter covers only the aspect of syllable but not the tonal aspect of homonym. In example (27), participant 12 used 合, a homonym of 和, to represent the meaning "together with". Both 合 and 和 not only share the same syllable, he, but also the tone, which is hé. Similarly, in example (28), participant 20 substituted 喜欢 with 习环. This example is obviously strategically applied because combination of $习$ and 环 does not exist in Mandarin. The Chinese characters $习$ and 
环 are put together to represent the sound xihuan. However, 习环 does not carry the same tone as 喜欢. 喜欢 is pronounced as xihuān (third tone and first tone) while 习环 is pronounced as xihuán (second tone and second tone). The created combination of $习$ and 环 implies that the strategy is formed based on syllable alone. The issue of tone was not in the consideration of participant 20.

Despite the difference in syllable and tone, the homonym in the form of Chinese characters is somehow helpful in passing across the message to the readers. By using this communication strategy of similar sounding Chinese characters, the phonetic clue is enough to guide the readers to guess the correct word and the intended meaning based on the sound of the homonym. This communication strategy of homonym can be possibly applied to other languages that have homonym as in Mandarin.

\section{Conclusion}

Usage of similar sounding words strategy is indeed a smart choice by the learners. By giving a phonetic link for others to find the target words, it provides constructive help in getting the message across despite the inaccurate pronunciation. Compared with other communication strategies such as topic avoidance, message abandonment and omission, using communication strategy of similar sounding words reflects the positive learning attitude and aggressive effort put in by the learners. It is, therefore, a strategy that should be encouraged in times of need. The results of this study also highlight a crucial issue about the learning problems in Chinese phonetics for foreign language learners.

The overall findings indicate that the learners attempted to communicate but were unable to get the accurate pronunciation due to the incomplete learning of Mandarin. In this study, the problems encountered by the Mandarin learners are clearly related to the construction of syllable, plosive, finals, affricate and fricative, especially alveolo-palatal, velar and retroflex sounds. In other words, the learners normally cannot master the typical unique Mandarin pronunciation which is not found in the learners' long acquired pronunciation system. The results, however, to our relief, shows that the learners are aware of the grouping of sounds. They will not, for example, substitute $t$ in the place of sh. The confusion is just within retroflex, velar or other similar sounds. Hence, more application in actual usage setting, or more drillings and exercises in classroom setting on these Chinese phonetic aspects in listening, speaking and reading are needed to increase the understanding and awareness of the learners to the usage and differences in phonetic systems. It has to be highlighted that the communication strategy of similar sounding words should not be seen as a failure of the learners but must instead be taken as an indicator for immediate remedial action and further improvement in foreign language teaching and learning.

\section{References}

Brown, H. D. (2000). Principles of language learning and teaching. New York, NY: Longman. 
Dornyei, Z., \& Scott, M. L. (1997). Communication strategies in a second language. definitions and taxonomies. Language Learning, 47(1), 173-210.

Everson, M.E. (1998). Word recognition among learners of Chinese as a foreign language: investigating the relationship between naming and knowing. The Modern Language Journal, 82(1), 194-204.

Hayes, E. B. (1987). The relationship between Chinese character complexity and character recognition. Journal of the Chinese Language Teachers Association, 22(1), 45-57.

Faérch, C., \& Kasper, G. (1983). Strategies in interlanguage communication. London: Longman.

Faérch, C., \& Kasper, G. (1984). Two ways of defining communication strategies. Language Learning, 34(1), 45-63.

$\mathrm{Ke}, \mathrm{C}$. (1996). An empirical study on the relationship between Chinese character recognition and production. The Modern Language Journal, 80(1), 340-350.

$\mathrm{Ke}, \mathrm{C}$. (1998). Effects of strategies on the learning of Chinese characters among foreign language students. Journal of the Chinese Language Teachers Association, 33(1), 93-112.

Kuo, L. J., Kim, T. J., Yang, X., Li, H., Liu, Y., Wang, H., \& Li, Y. (2015). Acquisition of Chinese characters: The effects of character properties and individual differences among second language learners. Frontiers in Psychology, 6, 110.

Lado, R. (1957). Linguistics across cultures. Ann Arbor, MI: University of Michigan Press.

Lam, K. C., Ang, L. H., Kuan, W. L., \& Hoe, F. T. (2018). Character recognition through wild association: an alternative in learning Chinese script for beginners. Issues in Language Studies, 7(1), 1-11.

Liberman, I. Y., Liberman, A. M., Mattingly, I., \& Shankweiler, D. (1980). Orthography and the beginning reader. In J. F. Kavanagh \& R. Venezky (Eds.), Orthography, reading, and dyslexia (pp. 137-153). Baltimore, MD: University Park Press.

Lin, Y. (2000). Vocabulary acquisition and learning Chinese as a foreign language (CFL). Journal of the Chinese Language Teachers Association, 35(1), 85-108.

McGinnis, M. (1999). Student goals and approaches. In Chu, M. (Ed.), Mapping the course of the Chinese language field (pp. 150-188). Kalamazoo: Chinese Language Teachers' Association.

Nemati, M., \& Taghizadeh, M. (2013). Exploring Similarities and Differences between L1 and L2. International Research Journal of Applied and Basic Sciences, 4(9), 2477-2483.

Poulisse, N. (1993). A theoretical account of lexical communication strategies. In R. Schreuder \& B. Weltens (Eds.), The bilingual lexicon (pp. 157-189). Amsterdam, Netherlands: John Benjamins

Ringbom, H. (2006). The importance of different types of similarity in transfer studies. In J. Arabski (Ed.) Cross-linguistic influences in the second language lexicon. Clevedon, England: Multilingual Matters. 
Sung, K. (2012). A study on Chinese-character learning strategies and character learning performance among American learners of Chinese. Chinese as a Second Language Research, 1(2), 193-210.

Yang, J. (2000) Orthographic effect on word recognition by learners of Chinese as a foreign language. Journal of the Chinese Language Teachers Association, 35(1), 1-18.

Yule, G., \& Tarone, E. (1987). Eliciting the performance of strategic competence. In R. Scarcella, E. Anderson \& S. Krashen (Eds.), Developing communicative competence (pp. 180-192). New York, NY: Harper and Row.

Wang, M., Cheng, C., \& Chen, S-W. (2006). Contribution of morphological awareness to Chinese-English biliteracy acquisition. Journal of Educational Psychology, 98(3), 542-553.

\section{Acknowledgement}

This research is funded by Universiti Putra Malaysia under the Putra Grant vote 9515500 . 